\title{
ASSESSMENT OF DRUG SUSCEPIIBILITY AND BIOFILM FORMATION ABILITY OF CLINICAL STRAINS OF LISTERIA MONOCYTOGENES
}

\author{
Krzysztof Skowron ${ }^{1} \odot$, Klaudia Brozek ${ }^{1}$, Magdalena Lukasik ${ }^{1}$, Natalia Wiktorczyk ${ }^{1} \odot$, \\ Jakub Korkus ${ }^{2} \odot$, Eugenia Gospodarek-Komkowska' ${ }^{1}$
}

${ }^{1}$ Department of Microbiology, Nicolaus Copernicus University in Toruń, Collegium Medicum of L. Rydygier in Bydgoszcz, Poland
${ }^{2}$ Department of Food Hygiene and Consumer Health, Wroclaw University of Environmental and Life Sciences, Wrocław, Poland

\section{ABSTRACT}

INTRODUCTION: Listeria monocytogenes is a cause of listeriosis, which is dangerous especially for the elderly, immunocompromised people, and pregnant women. The ability of these pathogens to colonise biotic and abiotic surfaces and form biofilm poses a serious threat for hospitalised, catheterised patients.

MATERIAL AND METHODS: The study was conducted on 29 L. monocytogenes strains isolated from clinical materials (blood, cerebrospinal fluid, swabs from vagina) and the reference strain L. monocytogenes ATCC 1911. The ability of the tested strains to form biofilm in 96-well plates and their drug susceptibility (disk diffusion method) was determined.

RESULTS: All strains formed biofilm, but its intensity was correlated with the source of isolation. A strong biofilm formed in $72.73 \%$ of isolates from cerebrospinal fluid [(A570 $0.421-1.3), 75.0 \%$ of blood isolates 9 (A570 0.389-1.063), and $50.0 \%$ of isolates from vaginal swabs (A570 0.457-0.487)]. The strongest biofilm was formed by strains derived from cerebrospinal fluid whereas isolates from vaginal swabs, which strongly formed a biofilm, accounted for $50.0 \%$ of the studied population (absorbance $0.457-0.487$ ).

It was found that $93.1 \%(n=27)$ of strains were susceptible to all drugs tested. Two strains $(6.9 \%)$ were resistant to cotrimoxazole and one strain (3.45\%) to erythromycin.

CONCLUSIONS: The diverse ability of clinical L. monocytogenes strains to form biofilm is an important aspect in the prophylaxis of catheterised patients.

KEY WORDS: Listeria monocytogenes; biofilm; crystal violet; drug susceptibility

Disaster Emerg Med J 2020; 5(1): 12-18

\section{INTRODUCTION}

L. monocytogenes is a Gram-positive, relatively anaerobic, widely distributed in nature (water, soil, wastewater), bacterium causing listeriosis [1]. The most susceptible to listeriosis are: elderly and immunocompromised people as well as pregnant women and newborns. L. monocytogenes has the ability to cross natural human barriers: the blood-brain, in- testinal, and placental barrier [2]. L. monocytogenes may cause mild infections such as gastroenteritis or contribute to more severe infections affecting the central nervous system (CNS) [3]. Clinical symptoms include fever, nausea and vomiting, diarrhoea, and in the case of invasive forms: bacteraemia and meningitis [4]. In recent years, there have been numerous cases of meningitis caused by $L$. monocytogenes 
worldwide. The incidence is estimated at 0.05 and 0.2 cases per 100,000 population [5].

Bacterial biofilms are found on almost every surface in the natural, medical, and industrial environment. In the hospital environment, bacterial biofilms occur, among others, on catheters and implants (e.g. heart valves) leading to difficulties in treatment and chronic infections [6]. L. monocytogenes colonises and forms biofilm both on biotic and abiotic surfaces. The structure of the biofilm increases bacterial resistance to antibiotics as well as the immune response of the host $[7,8]$. In addition, sub-lethal doses of antibiotics may increase the formation of bacterial biofilm, which hinders the treatment process $[9,10]$. Microorganisms that form biofilms often cause infections that are difficult to detect using conventional culturing methods [11].

The objective of this study was to assess the ability of biofilm formation using crystal violet and drug susceptibility of $L$. monocytogenes strains isolated from clinical materials.

\section{Material}

\section{MATERIAL AND METHODS}

The material for the study consisted of 29 strains of $L$. monocytogenes isolated from clinical materials [blood (BL), cerebrospinal fluid (CSF), vaginal swab (VS)] and the reference strain L. monocytogenes ATCC 1911. The tested strains are the part of collection of Department of Microbiology, L. Rydygier Collegium Medicum in Bydgoszcz of the Nicolaus Copernicus University in Toruń.

The species identification of the cultured strains was carried out using the MALDI TOF MS apparatus (Bruker), according to the manufacturer's instructions.

\section{Assessment of biofilm formation using crystal violet (CV)}

Bacteria were grown for 24 hours, and suspensions of 0.5 McFarland scale density in Mueller Hinton broth (MHB, Becton Dickinson) were prepared. Then, $20 \mu$ lof each suspension was added, in triplicate, to 96-well plates containing $180 \mu \mathrm{l}$ of sterile MHB medium. The negative control was $200 \mu$ l of sterile MHB medium. The positive control was the strain Staphylococcus aureus ATCC 35556, for which intensive biofilm formation has been proven. The culture plates were incubated for 24 hours $\left(37^{\circ} \mathrm{C}\right)$ in a humid chamber. Next, the bacterial suspension was removed, and each well was rinsed three times with sterile distilled water and air-dried (20 minutes, $\left.37^{\circ} \mathrm{C}\right)$. Then methanol $(200 \mu \mathrm{l}$, Avantor) was added to the wells and the plates were shaken (400 rpm, 20 minutes, $25^{\circ} \mathrm{C}$ ). The methanol was removed and the wells were air-dried. A water solution of $0.1 \%$ crystal violet ( $200 \mu \mathrm{L}$, Merck) was then added and plates were shaken (400 rpm, 20 minutes, $25^{\circ} \mathrm{C}$ ). Crystal violet was subsequently removed, and the plates were rinsed with water to obtain colourless washings and allowed to evaporate $\left(20\right.$ minutes, $\left.37^{\circ} \mathrm{C}\right)$. After drying, methanol $(200 \mu \mathrm{l})$ was added to each well and plates were shaken ( $400 \mathrm{rpm}, 5$ minutes, $25^{\circ} \mathrm{C}$ ). Absorbance was measured at $570 \mathrm{~nm}$ wavelength (BIO-TEK spectrophotometer, Synergy HT Multi-detection) using the KC4 v3.4 and KC4 Signature program.

\section{Evaluation of drug resistance of $L$. monocytogenes strains}

Antibiotic susceptibility assessment was made using the disk-diffusion method. Bacteria from 24hour Columbia Agar with $5.0 \%$ sheep blood plates ( $C A B$, bioMérieux) were used to prepare suspensions (0.5 McF) in $0.9 \%$ saline (Avantor). The suspensions of $100 \mu \mathrm{L}$ were spread on Mueller Hinton Agar with the addition of $5.0 \%$ equine blood and $20 \mu \mathrm{g} / \mathrm{ml}$ $\beta$-NAD (MHF, bioMérieux). Sensitivity of isolates to: penicillin $(1 \mu \mathrm{g})$, ampicillin $(2 \mu \mathrm{g})$, meropenem $(10 \mu \mathrm{g})$, erythromycin $(15 \mu \mathrm{g})$, and cotrimoxazole $(1.25-23.75 \mu \mathrm{g})$ were assessed. Antibiograms were incubated at $35^{\circ} \mathrm{C}$ for 20 hours. After the incubation period, growth inhibition zones were measured. Interpretation of the results was made in accordance with the EUCAST v.8.0 recommendations [12].

\section{Statistical analysis}

The intensity of biofilm formation (CV method) was determined based on the measured absorbance values. The studied strains were divided, depending on the strength of biofilm formation and metabolic activity in the biofilm, into three groups: weak biofilm ( $T-2 T)$, medium biofilm ( $>2 T-4 T)$, and strong biofilm ( $>4 \mathrm{~T})$. The value of $\mathrm{T}$, calculated from the formula $T=x n c+3 \delta$, for $C V$ is 0.091 .

The arithmetic mean for the absorbance values was calculated for each L. monocytogenes strain tested. The obtained results were subjected to statistical analysis in the Statistica 12 PL program (StatSoft). ANOVA with the Tukey post-hoc test was used to determine significant differences between strains in the ability to form biofilm. 
Based on the chi-square test and Fisher's exact test, differences in the frequency of individual drug resistance profiles between strains of different origin were checked. The correlation between the number of antibiotics that the strain was resistant to and the intensity of biofilm formation was also assessed. Significance was set at $\mathrm{p}<0.05$.

\section{RESULTS \\ Biofilm formation intensity}

It was shown that all tested strains formed a biofilm, but the intensity of its formation varied.

Among the tested strains, $66.67 \%(n=20)$ were characterised by strong biofilm formation ability, whereas $33.33 \%(n=10)$ of strains were classified into the group of medium biofilm formation intensity. There were no strains with weak biofilm formation ability. The intensity of biofilm formation correlated with the origin of isolates. Strong biofilm formation ability was found in eight $(72.73 \%)$ strains from cerebrospinal fluid (absorbance 0.421-1.3), nine (75.0\%) blood isolates (absorbance $0.389-1.063)$, and three (50.0\%) strains from the vagina (absorbance $0.457-0.487$ ). The most intense biofilm was created by strains derived from cerebrospinal fluid (mean absorbance value $-0.616 \pm 0.341$ ), which was significantly higher than the values established for vaginal strains $(0.354 \pm 0.147)$ and the reference strain $(0.357 \pm 0.076)$ (Fig. 1). The weakest biofilm-formers were found among strains isolated from the vagina (Fig. 2).

\section{Drug resistance of $L$. monocytogenes strains tested}

Among the 29 tested strains, resistance to cotrimoxazole was demonstrated in two (6.9\%) strains, one from cerebrospinal fluid and one from vaginal smear. Erythromycin resistance was found in one $(3.45 \%)$ isolate from cerebrospinal fluid.

Three drug resistance profiles were distinguished (Table 1). Profile I included 27 (93.1\%) strains sensitive to all antibiotics tested, of which 12 (100.0\%) were blood isolates, 10 (90.91\%) were strains isolated from the cerebrospinal fluid, and five (83.33\%) were isolates from the vaginal smear (Tab. 1). This profile was statistically rare among strains originating from vaginal smear. Profile II included one (3.45\%) strain isolated from the cerebrospinal fluid, which was resistant to both erythromycin and cotrimoxazole. In turn, profile III comprised one (3.45\%) strain isolated from a vaginal smear, in which resistance to cotrimoxazole was confirmed (Tab. 1).

There was no correlation (Guillford scale, correlation coefficient 0.211 ) between drug susceptibility of $L$. monocytogenes strains and the intensity of biofilm formation (Fig. 3).

\section{DISCUSSION}

It siniquitousness and the ability to form biofilms makes $L$. monocytogenes a serious pathogen, posing a threat to a wide range of patients. A particular risk group are catheterised patients. Due to its ability to produce biofilm, L. monocytogenes is more resistant to antibiotics, host immune system [7, 8], biocides, or stress $[13,14]$. L. monocytogenes can produce biofilms on various surfaces used in medicine or industry, such as polystyrene, glass, and stainless steel $[15,16]$.

It was shown that all tested strains of L. monocytogenes formed a biofilm, but the intensity of its formation varied. As much as $66.67 \%(n=20)$ of strains were characterised by a strong biofilm intensity, while $33.33 \%(n=10)$ were characterised by medium intensity. Similar results were obtained by Cirkovic et al. (2016) [19], who showed that $66.67 \%$ $(n=8)$ of $L$. monocytogenes were strong biofilm formers, $25.0 \%(n=3)$ medium biofilm formers, and $8.33 \%(n=1)$ weak biofilm formers. In contrast, Raby et al. (2016) [17] demonstrated medium and strong biofilm formation ability in $60.0 \%$ $(n=18)$ and $40.0 \%(n=12)$ of clinical strains, respectively. The strong and moderate ability of biofilm formation of clinical L. monocytogenes strains was also revealed by Borges et al. (2011) [18]. They confirmed that $68.0 \%$ of strains were characterised by medium intensity of biofilm formation whereas only $35.0 \%$ formed strong biofilm. In turn, Barbosa et al. (2013) [20] found that $70.3 \%$ of $(n=83)$ L. monocytogenes clinical strains formed a weak biofilm, and only $3.4 \%(n=4)$ were strong biofilm formers [20]. Similar results were obtained by Doijad et al. (2015) [21], who showed that as much as $65.63 \%(n=21)$ were characterised by low intensity of biofilm formation and $34.38 \%(n=11)$ by medium biofilm intensity [21].

It was shown that strains isolated from cerebrospinal fluid formed biofilm the most intensively (average absorbance value - 0.616). On the other hand, the weakest biofilm formers were isolated from vaginal swabs (mean absorbance val- 


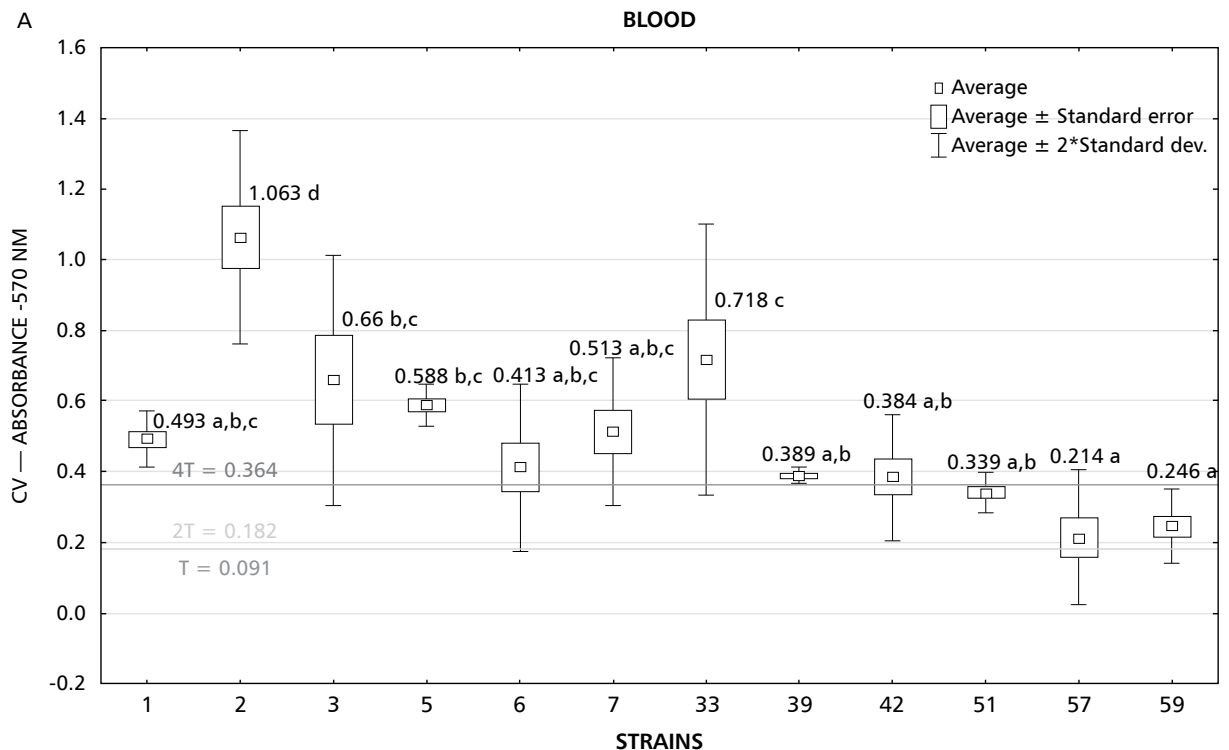

B

CEREBROSPINAL FLUID

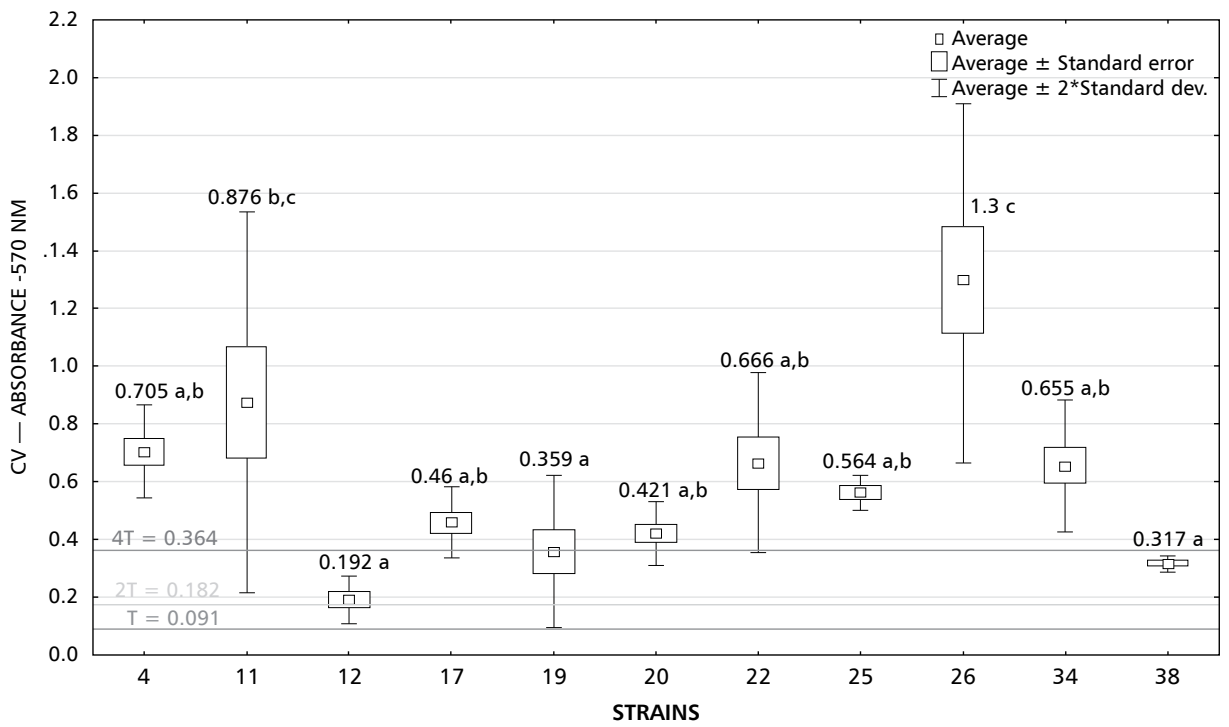

C

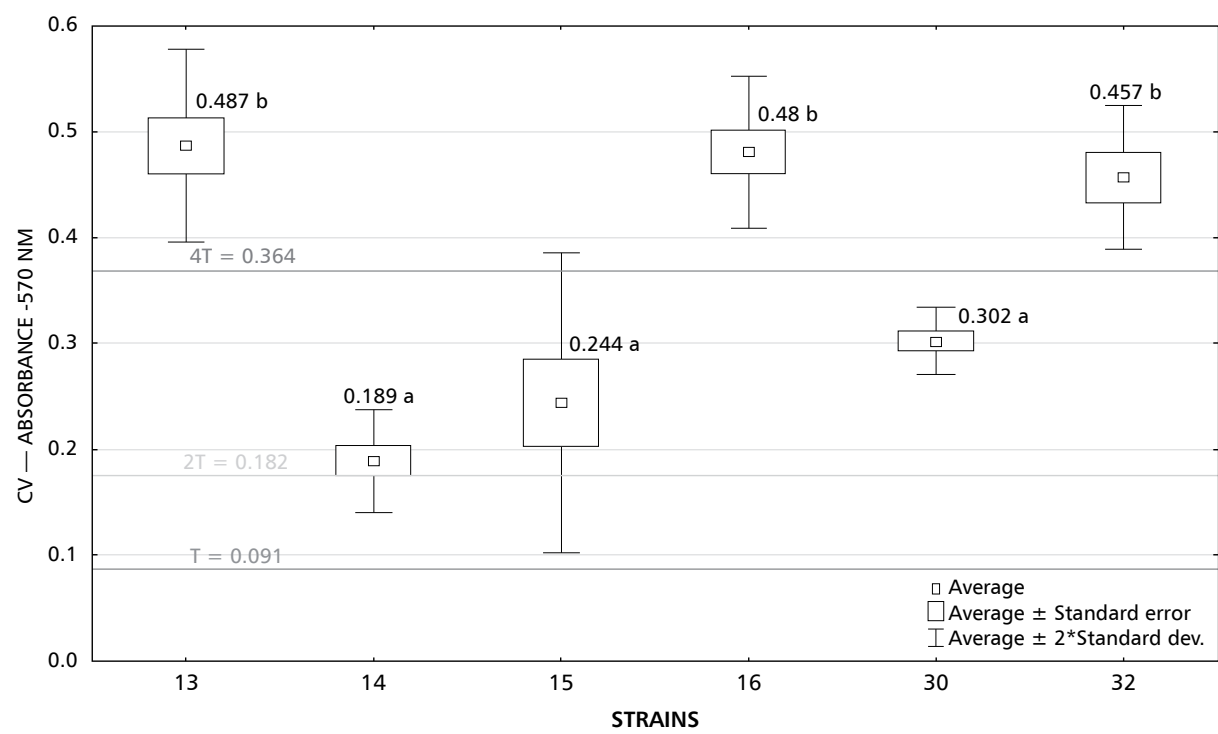

FIGURE 1. A. The intensity of biofilm formation among L. monocytogenes strains isolated from blood; B. Intensity of biofilm formation among L. monocytogenes strains isolated from cerebrospinal fluid; $\mathbf{C}$. Intensity of biofilm formation among L. monocytogenes strains isolated from vaginal swabs; ( $a, b, c, d 3$ values marked with different letters differ statistically significantly, $p \leq 0.05$ ) 


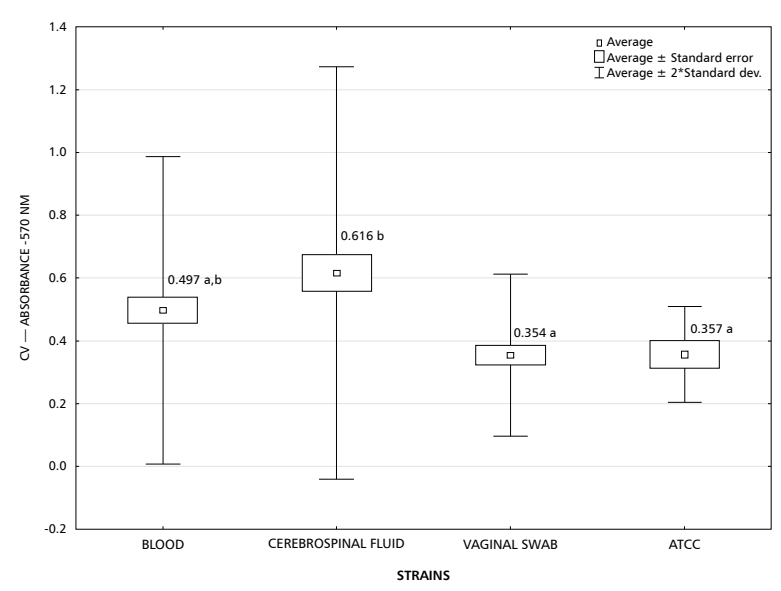

FIGURE 2. Comparison of mean values of absorbances obtained by $C V$ between groups of $L$. monocytogenes strains $(a, b-v a l-$ ues marked with different letters differ significantly between each other, $\mathrm{p} \leq 0.05$ )

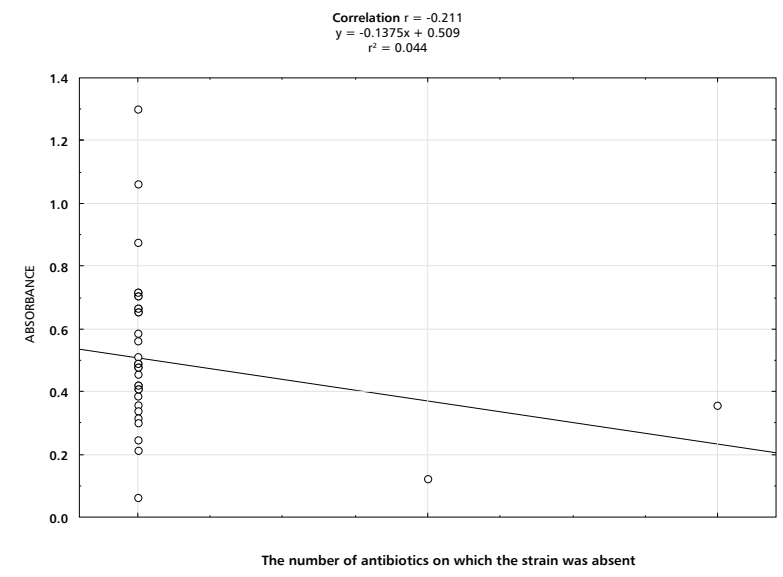

FIGURE 3. Correlation between the number of antibiotics to which the strain is resistant and the intensity of biofilm formation by L. monocytogenes

\begin{tabular}{|c|c|c|c|c|}
\hline \multirow{2}{*}{$\begin{array}{l}\text { The name of the drug resistance } \\
\text { profile }\end{array}$} & \multirow{2}{*}{$\begin{array}{c}\text { Drug resistance profile } \\
\mathrm{BL}\end{array}$} & \multicolumn{3}{|c|}{ Number of strains depending on the origin [n, \%] } \\
\hline & & CSF & VS & \\
\hline I & $\begin{array}{l}\text { S: P, AM, E, MEM, SXT } \\
\text { R: --- }\end{array}$ & $12(100.0 \%)^{a}$ & $10(90.91 \%)^{a}$ & $5(83.33 \%)^{b}$ \\
\hline$\|$ & $\begin{array}{l}\text { S: P, AM, MEM, } \\
\text { R: E, SXT }\end{array}$ & $0^{\mathrm{a}}$ & $1(9.09 \%)^{b}$ & $0^{\mathrm{a}}$ \\
\hline III & $\begin{array}{l}\text { S: P, AM, E, MEM, } \\
\text { R: SXT }\end{array}$ & $0^{\mathrm{a}}$ & $0^{a}$ & $1(16.67 \%)^{b}$ \\
\hline Total $[n, \%]$ & & $12(100.0 \%)$ & $11(100.0 \%)$ & $6(100.0 \%)$ \\
\hline
\end{tabular}

$a, b-$ values marked with different letters differ significantly statistically $(p<0.05)$

ue -0.354$)$. There are no data on the intensity of biofilm formation of $L$. monocytogenes isolated from different clinical materials. The study of Raby et al. (2016) [17] showed that strains of L. monocytogenes isolated from food produced a significantly stronger biofilm $(p \leq 0.05)$ than the strains isolated from clinical material. Also, Doijad et al. (2015) [21] showed that the intensity of biofilm formation is correlated with the isolation source of the strain. Among animal isolates $34.38 \%(n=11)$ were characterised by moderate biofilm formation intensity whereas $65.63 \%(n=21)$ formed weak biofilm [21]. Among human isolates $55.56 \%(n=10)$ showed a weak biofilm formation rate, and $44.44 \%$ $(n=8)$ were classified as biofilm-forming strains. In contrast, among strains isolated from meat, only $14.29 \%(n=2)$ were classified into the strains with moderate biofilm intensity and as much as $85.71 \%$ $(n=12)$ were strains with low intensity. No strain isolated from these sources showed strong biofilm formation. On the other hand, among strains isolated from milk and milk products, $26.46 \%(n=9)$ showed a strong biofilm formation ability, $17.65 \%$ $(n=6)$ of strains were moderate biofilm formers, and $55.88 \%(n=19)$ were classified as strains of weak biofilm [21].

In our own study it was shown that $93.1 \%$ $(n=27)$ of strains were sensitive to all tested antibiotics. In two (6.9\%) strains cotrimoxazole resistance was demonstrated, and in one (3.45\%) strain - resistance to erythromycin. All isolates were sensitive to penicillin, ampicillin, and meropenem. Also, Raby et al. (2016) [17] showed that the majority of clinical strains $83.33 \%(n=25)$ were susceptible to the tested antibiotics. However, they found three $(10.0 \%)$ strains and two (6.67\%) strains resistant to meropenem and penicillin, respectively [17]. The study of Winiarska (2017) [22] also revealed one strain resistant to meropenem and additionally three (30.0\%) erythromycin-resistant strains, whereas 
Borcan et al. (2014) [23] showed resistance to ampicillin $(7.7 \%, \mathrm{n}=2)$, penicillin $(7.7 \%, \mathrm{n}=2)$, and erythromycin $(3.85 \%, \mathrm{n}=1)$. In turn, in the studies of Madeo et al. (2015) [24] and Caplan et al. (2014) [25] susceptibility to penicillin, meropenem, and erythromycin in all clinical isolates of L. monocytogenes was reported.

\section{Conclusions}

The results of our study show that $L$. monocytogenes strains isolated from clinical materials are characterised by a diverse ability to form biofilm. Therefore, it is recommended to control biofilm formation in catheterised patients.

\section{Conflict of interest: The authors declare no conflict of interest.}

Funding Sources: This research was financially supported by the Nicolaus Copernicus University with funds from the maintenance of the research potential of the Department of Microbiology (DS-UPB).

\section{REFERENCES}

1. Muskalska KB, Szymczak B. Postępy badań nad bakteriami rodzaju Listeria. Post Mikrobiol. 2015; 54(2): 123-132.

2. Vázquez-Boland $\mathrm{JA}$, Kuhn $\mathrm{M}$, Berche $\mathrm{P}$, et al. Listeria pathogenesis and molecular virulence determinants. Clin Microbiol Rev. 2001; 14(3): 584-640, doi: 10.1128/CMR.14.3.584-640.2001, indexed in Pubmed: 11432815.

3. Godziszewska S, Musioł E, Duda I. Listeriosis - a dangerous, contagious disease. Meningitis caused by Listeria monocytogenes - case report. Annales Academiae Medicae Silesiensis. 2015; 69: 118-124, doi: 10.18794/aams/33100.

4. Allerberger $F$, Wagner M. Listeriosis: a resurgent foodborne infection. Clin Microbiol Infect. 2010; 16(1): 16-23, doi: 10.1111/j.14690691.2009.03109.x, indexed in Pubmed: 20002687.

5. Pelegrín I, Moragas M, Suárez C, et al. Listeria monocytogenes meningoencephalitis in adults: analysis of factors related to unfavourable outcome. Infection. 2014; 42(5): 817-827, doi: 10.1007/s15010-0140636-y, indexed in Pubmed: 24902522.

6. Pokrowiecki R, Tyski S, Zaleska M. Problematyka Zakażeń Okołowszczepowych. Post Mikrobiol. 2014; 53: 123-134.

7. Mah TF, $0^{\prime} T o o l e ~ G A$. Mechanisms of biofilm resistance to antimicrobial agents. Trends Microbiol. 2001; 9(1): 34-39, doi: 10.1016/s0966842x(00)01913-2, indexed in Pubmed: 11166241.

8. Anderson GG. O'Toole G.A.: Innate and induced resistance mechanisms of bacterial biofilms. Bacterial Biofilms red. Romeo T. Springer Berlin Heidelberg. 2008: 85-105.

9. Bagge $N$, Schuster $M$, Hentzer $M$, et al. Pseudomonas aeruginosa biofilms exposed to imipenem exhibit changes in global gene expres- sion and beta-lactamase and alginate production. Antimicrob Agents Chemother. 2004; 48(4): 1175-1187, doi: 10.1128/aac.48.4.11751187.2004, indexed in Pubmed: 15047518.

10. Hoffman LR, D'Argenio DA, MacCoss MJ, et al. Aminoglycoside antibiotics induce bacterial biofilm formation. Nature. 2005; 436(7054): 1171-1175, doi: 10.1038/nature03912, indexed in Pubmed: 16121184.

11. de la Fuente-Núñez C, Reffuveille F, Fernández L, et al. Bacterial biofilm development as a multicellular adaptation: antibiotic resistance and new therapeutic strategies. Curr Opin Microbiol. 2013; 16(5): 580589, doi: 10.1016/j.mib.2013.06.013, indexed in Pubmed: 23880136.

12. European Committee on Antimicrobial Susceptibility Testing: Breakpoints tables for interpretation of MICs and zones diameters. 2018. Version 8.0. http://www.eucast.org.

13. Holch A, Webb K, Lukjancenko O, et al. Genome sequencing identifies two nearly unchanged strains of persistent Listeria monocytogenes isolated at two different fish processing plants sampled 6 years apart. Appl Environ Microbiol. 2013; 79(9): 2944-2951, doi: 10.1128/ AEM.03715-12, indexed in Pubmed: 23435887.

14. Nowak J, Cruz CD, Tempelaars M, et al. Persistent Listeria monocytogenes strains isolated from mussel production facilities form more biofilm but are not linked to specific genetic markers. Int J Food Microbiol. 2017; 256: 45-53, doi: 10.1016/j.ijfoodmicro.2017.05.024, indexed in Pubmed: 28599174.

15. Di Bonaventura G, Piccolomini R, Paludi D, et al. Influence of temperature on biofilm formation by Listeria monocytogenes on various food-contact surfaces: relationship with motility and cell surface hydrophobicity. J Appl Microbiol. 2008; 104(6): 1552-1561, doi: 10.1111/j.1365-2672.2007.03688.x, indexed in Pubmed: 18194252.

16. Tomicic $R$, Cabarkapa I, Vukmirovic $D$, et al. Influence of growth conditions on biofilm formation of Listeria monocytogenes. Food and Feed Research. 2016; 43(1): 19-24, doi: 10.5937/ffr1601019t.

17. Raby $S$. Porównanie zdolności tworzenia biofilmu przez szczepy Listeria monocytogenes izolowane z zakażeń i żywności. Master's Thesis. 2016.

18. Borges SF, Silva JGL, Teixeira PCM. Survival and biofilm formation of Listeria monocytogenes in simulated vaginal fluid: influence of pH and strain origin. FEMS Immunol Med Microbiol. 2011; 62(3): 315-320, doi: 10.1111/j.1574-695X.2011.00815.x, indexed in Pubmed: 21569122.

19. Cirkovic I, Bozic DD, Draganic V et al. Licheniocin 50.2 and Bacteriocins from Lactococcus lactis subsp. lactis biovar. diacetylactis BGBU1-4 Inhibit Biofilms of Coagulase Negative Staphylococci and Listeria monocytogenes Clinical Isolates. PLoS One. 2016; 11(12): e0167995, doi: 10.1371/journal.pone.0167995, indexed in Pubmed: 27930711.

20. Barbosa J, Borges S, Camilo R, et al. Biofilm Formation among Clinical and Food Isolates of Listeria monocytogenes. Int J Microbiol. 2013; 2013: 524975, doi: 10.1155/2013/524975, indexed in Pubmed: 24489549.

21. Doijad SP, Barbuddhe SB, Garg S, et al. Biofilm-Forming Abilities of Listeria monocytogenes Serotypes Isolated from Different Sources. 2015. 
22. Winiarska K. Porównanie częstości występowania genów kodujących wybrane czynniki wirulencji szczepów Listeria monocytogenes izolowanych z przypadków klinicznych i żywności. Master's Thesis. 2017.

23. Borcan AM, Huhulescu S, Munteanu A, et al. Listeria monocytogenes - characterization of strains isolated from clinical severe cases. J Med Life. 2014; 7 Spec No. 2: 42-48, indexed in Pubmed: 25870672.

24. Madeo M, Musumeci R, Careddu AM, et al. Antimicrobial susceptibility of Listeria monocytogenes isolates from human cases in northern Italy, 2008-2010: MIC determination according to EUCAST broth microdilution method. J Chemother. 2015; 27(4): 201-206, doi: 10.1179/1973947814Y.0000000187, indexed in Pubmed: 24720267.

25. Caplan M, Mateescu L, Dimov T, et al. Antibiotic Susceptibility Profiles of Listeria monocytogenes Strains Isolated from Food Products and Clinical Samples. Romanian Review of Laboratory Medicine. 2014; 22(2), doi: 10.2478/rrlm-2014-0014. 